\title{
DESIGNING PARTERRES ON THE MAIN CITY SQUARES
}

\author{
Milena Lakićević (D), Ivona Simić (iD), Radenka Kolarov \\ University of Novi Sad, Faculty of Agriculture, Horticulture and Landscape Architecture, \\ Novi Sad, Serbia
}

\begin{abstract}
A "parterre" is a word originating from the French, with the meaning interpreted as "on the ground". Nowadays, this term is widely used in landscape architecture terminology and depicts a groundlevel space covered by ornamental plant material. The designing parterres are generally limited to the central city zones and entrances to the valuable architectonic objects, such as government buildings, courts, museums, castles, villas, etc. There are several main types of parterres set up in France, during the period of baroque, and the most famous one is the parterre type "broderie" with the most advanced styling pattern. Nowadays, French baroque parterres are adapted and communicate with contemporary landscape design styles, but some traits and characteristics of originals are still easily recognizable. In this paper, apart from presenting a short overview of designing parterres in general, the main focus is based on designing a new parterre on the main city square in the city of Bijeljina in the Republic of Srpska. The design concept relies on principles known in the history of landscape art but is, at the same time, adjusted to local conditions and space purposes. The paper presents the current design of the selected zone parterre on the main city square in Bijeljina and proposes a new design strongly influenced by the "broderie" type of parterre. For creating a new design proposal we have used the following software AutoCad (for 2D drawings) and Realtime Landscaping Architect (for more advanced presentations and 3D previews). The paper provides detailed graphical representations for a new design proposal and explains the main design ideas and guidelines which can be applied even when designing parterres in the other urban space. Besides that, the paper lists the plant material that is suitable for establishing and maintaining parterres in the urban environment.
\end{abstract}

Key words: urban design, exterior design, Bijeljina, Republic of Srpska

\section{INTRODUCTION}

The modern design of urban areas includes green infrastructure and as an important and integral part of urban landscapes, and choosing appropriate design for different public and open spaces is crucial for the visual qualities of modern cities. When defining main ideas and guidelines for an urban open space design one can rely on the heritage of previous epochs (Lakićević and Kordić, 2018). When choosing a certain epoch as a starting point for the design process, it is essential to update the old patterns and to communicate with the present styles and design concepts. There are two main styles in landscape architecture: geometric and landscape style (Kolarov et al, 2020). Geometric style uses strict geometric forms, while landscape style is characterized by irregular lines and shapes. The geometric style is used on the small city squares and at the entrances to the important architectural objects, and landscape style is applied over large areas and suburban zones.

Geometric style reached its peak in the period of baroque in France, and the most famous examples are Versailles Park and Park of Vaux-le-Vicomte, both designed by André le Nôtre in the $17^{\text {th }}$ century. After the baroque epoch, the geometric style reduced many elements, retaining in most cases only symmetry and perspective principles (Motloch, 2001). However, French gardens are a valuable cultural heritage and carry within important constructive lessons. French baroque gardens are famous for their parterres, and there were several types of parterres in this period. The French word "parterre" literary means "on the ground", as this is a ground-level space covered with plant material. Depending on the type of plant material, we recognize English parterre (consisted of lawns predominately), water parterre (with fountains, water cascades, etc.), shaped parterre (with topiary forms, inspired by the Italian renaissance period), etc. The most complex type of French parterre is the one called "broderie", well-known for highly ornamental and colourful appearance (Lohmann, 1963). This type of parterre in some modified form can be seen in many cities worldwide. Usually, they are situated in front of the monumental architectural objects. In this paper, we present the use of French parterre in the contemporary landscape design on the example of the main square in the city of Bijeljina in the Republic of Srpska. 


\section{METHODS}

The chosen location is the Square King Peter I Karadjordjevic, in Bijeljina, in the Republic of Srpska (Figure 1). The goal of the paper is to propose a new design for this square, inspired by the French baroque style. The selected area is located in front of the building of the City Administration of the Municipality of Bijeljina in the city downtown area. The square has an elongated-semicircular shape and covers the area of $3,088 \mathrm{~m}^{2}$. Next to the square, there are many important objects: the Museum of Semberija, the National Library "Filip Visnjic", the building of the Court in Bijeljina, the Culture Centre, and the City Park. The main accent on this square is the monument of the King Peter I Karadjordjevic. The analyzed space is one of the main landmarks of the city, and therefore it is important to provide an adequate design for it.

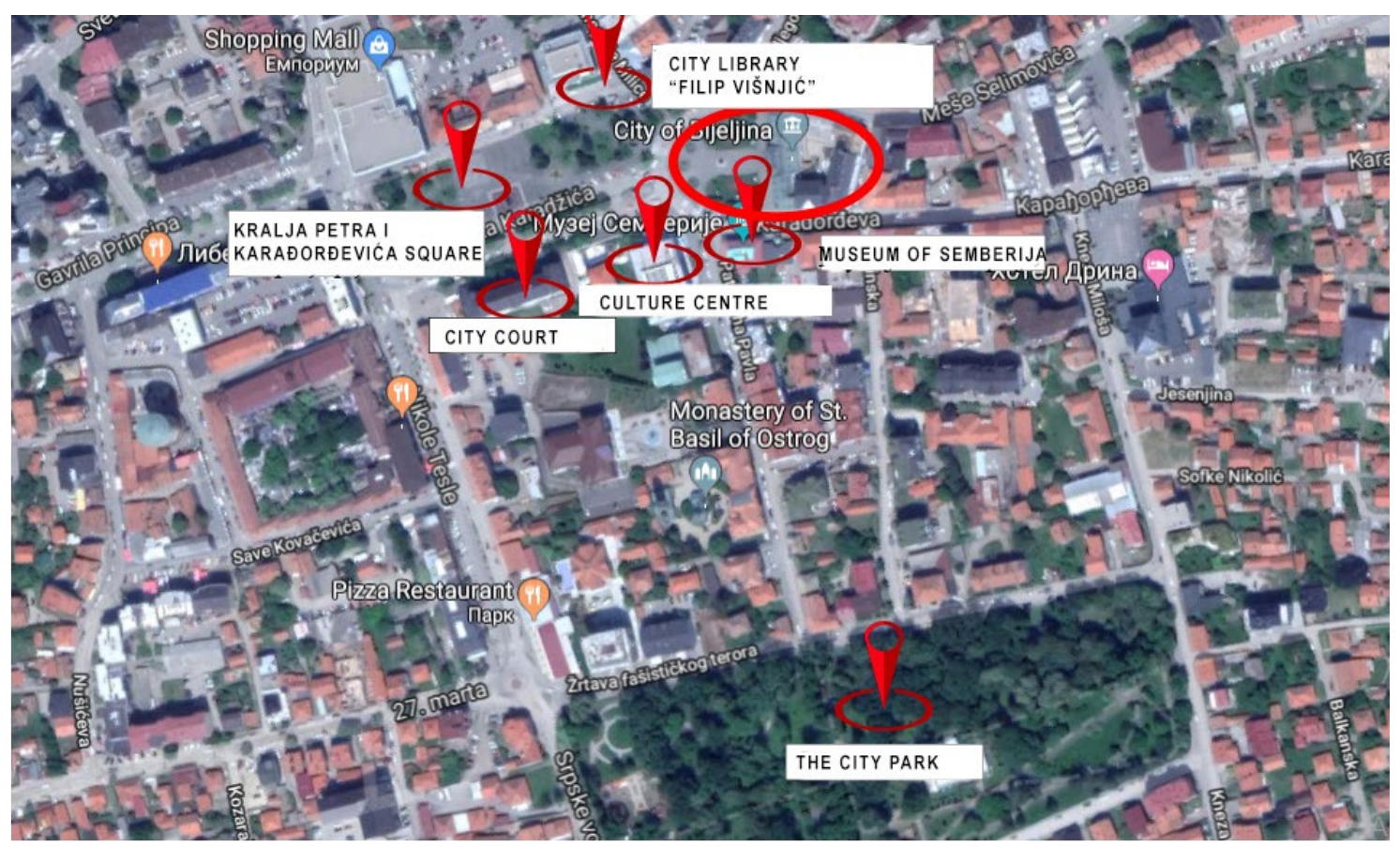

Figure 1: Location of the selected area

The square is symmetrically arranged with two grass- flower parterres that are located on both sides of the statue. There are also three circular fountains on the semicircular front of the plateau that emerge from variously designed sculptures (Figure 2). Along the edge of the parterre, there are benches on both sides and a row of medium-high trees with a decorative umbrella canopy. The plant material on this plateau consists, in addition to seasonal flower species, of lawn and trees of Acer platanoides 'Globosum'. In summer trees provide nice and cozy shade for people to sit there and rest, while in wintertime when branches are bare, they are decorated with New Year's lightning which affects and amplifies the holiday spirit in town. This public place provides multiple functions; it is used for different kinds of manifestations during the year, public gatherings, public speeches; people use it for short rest during the day, while in summer nights it becomes a popular spot to gather and hang out.

The newly proposed design follows the principles of "broderie" parterre, it combines plant material with so-called inorganic component (stones, bricks, sand, etc.) with the purpose of creating a visually appealing styling pattern. The idea is to create a high contrast between the background consisted of inorganic material and the plant components of the parterre. This way, the plant material is additionally emphasized and more effective in visual quality terms. The styling pattern of the "broderie" parterre may vary in a wide range, but in this example, we provided a design that is not so complex, and that can be easily and regularly maintained. The appearance of the new design proposal is illustrated in the Results section, Figures 3-5, and these figures should provide a clear overview of the designer's idea. The project idea is designed by the second author of this paper. 


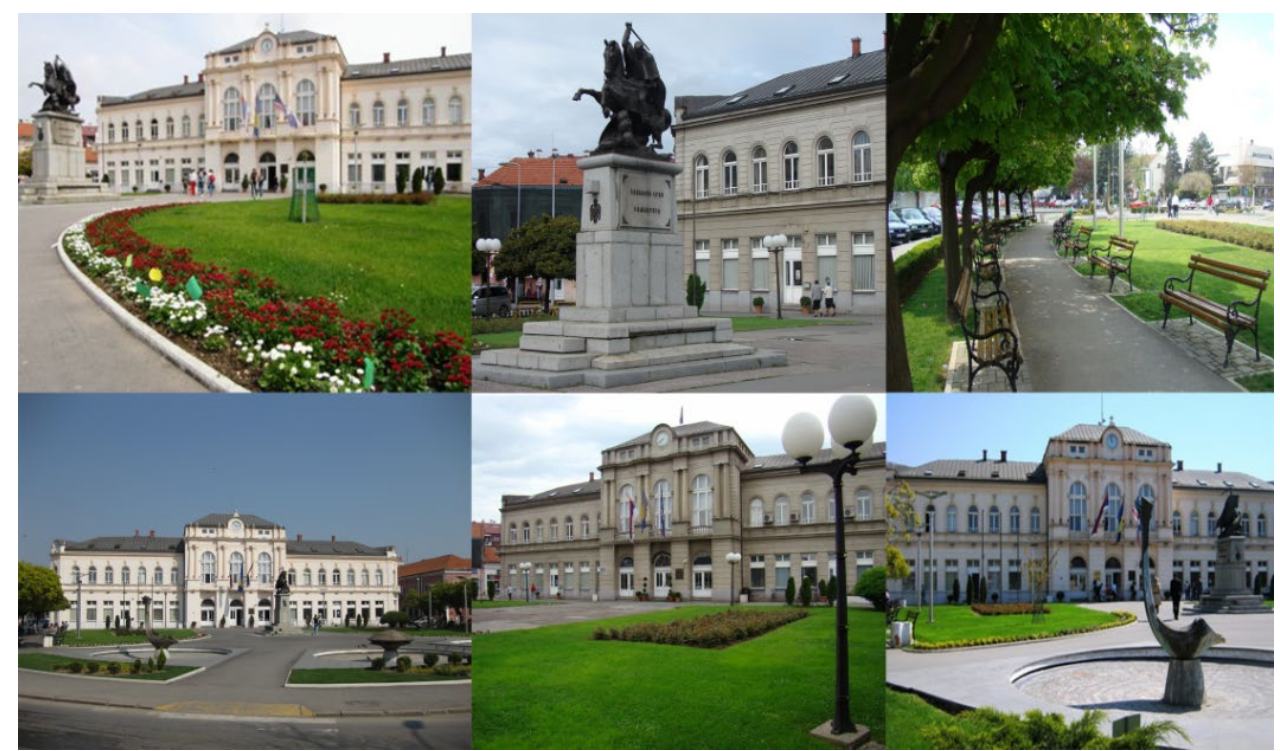

Figure 2: Photographies of the selected area

To visualize the new design solution, two software were used: AutoCAD 2017 for 2D presentations and drawings, and Realtime Landscaping Architect 2018 for creating 3D renderings.

\section{RESULTS AND DISCUSSION}

French Baroque style was a symbol of fame, power, and wealth in the $17^{\text {th }}$ century, therefore in order to fit in modern landscape design, it had to go along and follow the important object in town, such as the building of City Administration is. The structure of the building is representative, therefore it requires matching landscape design in front of it. In the newly designed project, the main focus has been kept on the statue of Peter I Karađorđević.

The Square is divided into twelve parterres that are different in shapes and sizes. There are four main parterres symmetrically arranged around the center motive of the square. Each of them is bordered with boxwood (Buxus sempervirens) and inside of them are striped alleys of flowers that are also framed with a boxwood border and together form a certain motive. In the area around the monument and the central parterres, it is planned to be a sitting area with few benches placed that people can use for longer or shorter rest. (Figure 3a; 3b).

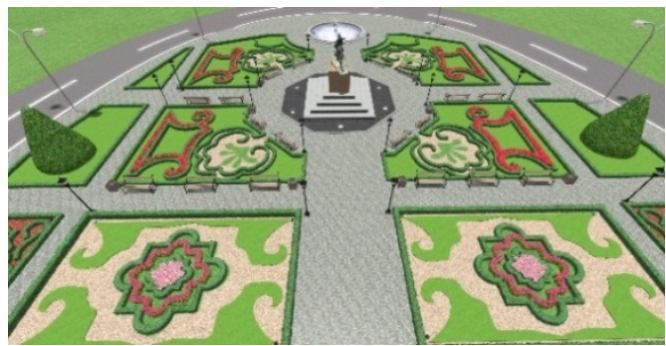

a)

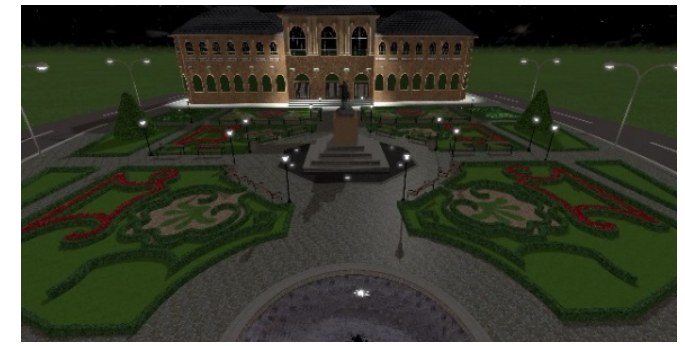

b)

Figure 3: a) View on the parterre in front of the building of the City Administration b) View on the parterre in front of the building of the City Administration at night

To the west, instead of three existing circular fountains, in new design is projected only one circular form of fountain with a bell-shaped overfall. The fountain gives a special effect, both visual and sound. Whole space can be seen from every point of the square; there are no visual obstacles in the form of tall bushes or trees. The forms of the ground floor are based on geometric principles, as the French Baroque style dictates. In front of the City Administration building, there are four "broderie" parterres. The side floors are bordered with boxwood and in the middle, there are also boxwood decorative 
shapes. There are no flowers in them, but we have a base sprinkled with reddish and bright mulch, which together with the boxwood motives give a special decorative effect and a contrast (Figure 4a).

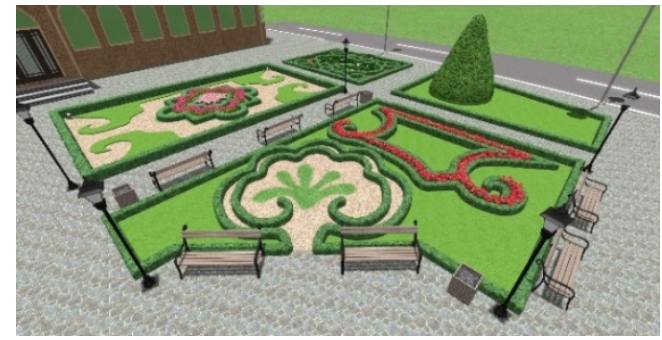

a)

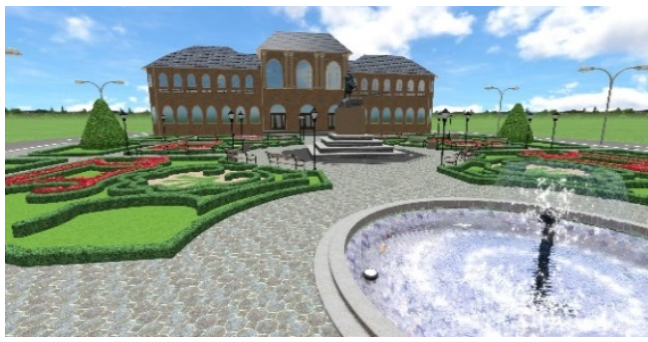

b)

Figure 4: a) Detail of embroidery parterre b) Detail of fountain

All parterres with their different shapes and sizes follow the semicircular form of the plateau and together with the fountain they round off the entire newly designed shape and create a synthesis between a strict geometric form, straight lines, and a rounded surface of the square.

In most parterres, the main element consists of the species of meadow, and therefore the lawns are based on the following ratio of grasses: - 50\% English lily (Lolium perenne) - 25\% meadow wig (Festuca pratensis) - 25\% red wig (Festuca rubra). Topiary forms of Thuja gigantea were used as accents on the side floors. Seasonal flowers are changed in the flower parterres and thus the possibility of planting different flower species during the year is given. An overview of all "broderie" parters is illustrated in Figure 5.

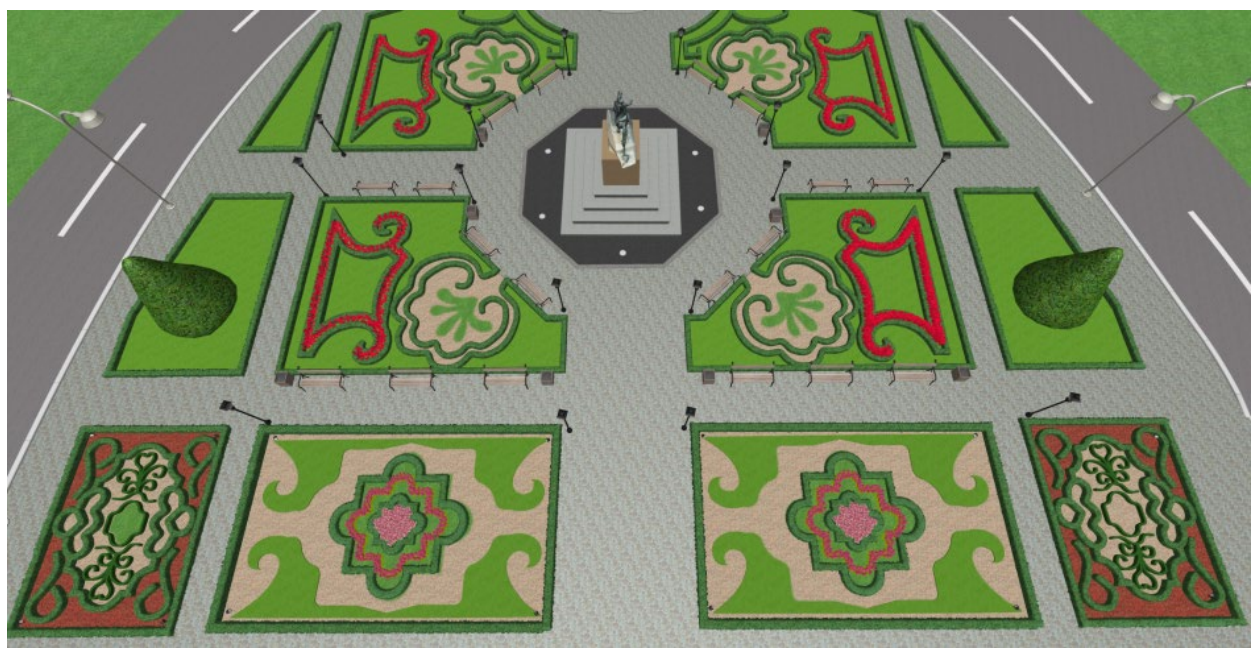

Figure 5: "Broderie" parterres

\section{CONCLUSION}

Nowadays, parterres inspired by French baroque are widely used within private gardens, but also in public areas. Generally, they are made of borders of boxwood, lavender, or rosemary the most. The low clipped hedges are laid out in a symmetrical pattern, these can be quite intricate or as simple as four squares next to each other with a gravel path separating them. Water is often a key feature of French garden design and lots of round pools and long rectangles of water will be incorporated, the reflection of the water adding to the symmetry and tranquility of the scene. Fountains and cascades are also very common features and widely used in modern design. Projects like the one we have presented through this research paper is an example of the application of the French Baroque landscape style in the modern age. Elements such as harmony, symmetry, "broderie" parterres, and water features are some of the key elements that we can recognize in many nowadays projects, that are inspired by French gardens from the $17^{\text {th }}$ and $18^{\text {th }}$ centuries. 


\section{REFERENCES}

[1] Kolarov, R., Lakićević, M., Gawryszewska, B.: "Design styles in landscape architecture", Proceedings of moNGeometrija 2020, (moNGeometrija, Serbia, 2020), pages: 1-9.

[2] Lakićević, M., Kordić, D.: "Geometric style in design of urban landscapes", Proceedings of $9^{\text {th }}$ International Symposium on Graphic Engineering and Design 2018, (GRID: Novi Sad, Serbia, 2018), pages 519-523.

[3] Lohmann, K.B.: "Fundamentals of Landscape Architecture", (International Correspondence Schools, Scranton, Pennsylvania, USA, 1963.).

[4] Motloch, J.L.: "Introductiontolandscapedesign", (Willey, Austin TX, 2001.), pages 134-146.

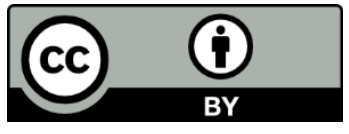

(C) 2020 Authors. Published by the University of Novi Sad, Faculty of Technical Sciences, Department of Graphic Engineering and Design. This article is an open access article distributed under the terms and conditions of the Creative Commons Attribution license 3.0 Serbia (http://creativecommons.org/licenses/by/3.0/rs/). 